OPEN ACCESS

Edited by:

Krystallenia I. Alexandraki, National and Kapodistrian University of Athens, Greece

Reviewed by: Polyzois Makras, 251 Hellenic Airforce \& VA General Hospital, Greece

Carl Friedrich Classen, University Hospital Rostock, Germany

${ }^{*}$ Correspondence:

Zhiyu Li zrlizy@zju.edu.cn

${ }^{\text {t}}$ These authors have contributed equally to this work

Specialty section: This article was submitted to Cancer Endocrinology, a section of the journal Frontiers in Endocrinology

Received: 26 September 2020 Accepted: 30 April 2021 Published: 19 May 2021

Citation:

Zhang J, Wang C, Lin C, Bai B, Ye M, Xiang D and Li Z (2021) Spontaneous

Thyroid Hemorrhage Caused by Langerhans Cell Histiocytosis: A Case Report and Literature Review. Front. Endocrinol. 12:610573. doi: 10.3389/fendo.2021.610573

\section{Spontaneous Thyroid Hemorrhage Caused by Langerhans Cell Histiocytosis: A Case Report and Literature Review}

\author{
Jingying Zhang ${ }^{1 \dagger}$, Chengchen Wang ${ }^{2 \dagger}$, Chuanshuai Lin ${ }^{1}$, Binglong Bai ${ }^{1}$, Mao Ye ${ }^{1}$, \\ Dapeng Xiang ${ }^{1}$ and Zhiyu $\mathrm{Li}^{1 *}$ \\ ${ }^{1}$ Department of Thyroid Surgery, School of Medicine, Second Affiliated Hospital of Zhejiang University, Hangzhou, China \\ 2 Department of General Surgery, Hangzhou Mingzhou Hospital, Hangzhou, China
}

Purpose: Langerhans cell histiocytosis $(\mathrm{LCH})$ is a rare clonal disorder of Langerhans antigen-presenting cells. However, thyroid LCH involvement is relatively rare. We present the first case of spontaneous thyroid hemorrhage due to LCH progression and discuss the clinical features, diagnosis, and treatments of thyroid LCH in a literature review.

Methods: Clinical data were collected. Previously published articles on thyroid LCH involvement were reviewed to assess the clinical features, diagnosis, and treatments for thyroid LCH.

Results: A 54-year-old female presented with a multi-system $\mathrm{LCH}$, affecting the uterus, liver, pituitary gland, and thyroid gland. Clinical stability was achieved after systemic chemotherapy. After 7 years of regular follow up, the patient complained of a sudden painful neck swelling and progressive dyspnea. Computed Tomography revealed bilateral goiter with hematoma, and the patient was diagnosed with spontaneous thyroid bleeding based on her clinical symptoms and radiological findings. The patient was incubated to relieve airway compromise and partial thyroidectomy was performed for definitive treatment. Pathological evaluation further confirmed the diagnosis of thyroid $\mathrm{LCH}$. The patient recovered well after surgery.

Conclusion: Spontaneous thyroid bleeding due to thyroid LCH progression is extremely rare. Treatments for $\mathrm{LCH}$ vary depending on the severity of the disease. We suggest that, for patients with multi-system LCH with thyroid lesion, long-term active surveillance of thyroid hormone concentrations, and thyroid gland volume is required. Physicians should be alert of the potentially life-threatening spontaneous thyroid hemorrhage when aggravated diffuse goiter and hypothyroidism appear. Further investigation is required to establish the guidelines for thyroid LCH treatment.

Keywords: Langerhans cell histiocytosis, thyroid, spontaneous thyroid hemorrhage, thyroidectomy, chemotherapy 


\section{INTRODUCTION}

Langerhans cell histiocytosis (LCH) is a rare disease caused by Langerhans cell clonal hyperplasia (1). It can involve several organs and tissues. Including the bones, the lungs, the skin, the liver, the lymph nodes, and the pituitary gland. Thyroid involvement is relatively rare and most commonly occurs as part of multi-system LCH (2). Clinical manifestations of $\mathrm{LCH}$ depend on the site of involvement. Common symptoms of bone $\mathrm{LCH}$ included painful masses and osteolytic lesions. LCH may cause diabetes insipidus when the pituitary gland is involved. Conversely, $\mathrm{LCH}$ with thyroid involvement mostly manifests as diffuse or nodular enlargement with or without hypothyroidism. Neck pain, dysphonia, and obstructive symptoms are rare (2). Although it is highly vascularized, spontaneous hemorrhage of the thyroid gland is rare and may cause lethal acute airway obstruction. In this article, we report the first case of a patient with spontaneous thyroid hemorrhage due to $\mathrm{LCH}$ involvement and further discuss the clinical features, diagnosis, and treatment for thyroid $\mathrm{LCH}$ in a literature review.

\section{CASE DESCRIPTION}

\section{Patient History}

A 54-year-old female patient presented to the local hospital with a sudden painful neck swelling and progressive dyspnea. A medical history revealed that the patient underwent an uterectomy due to a uterine mass, which was suspected of malignancy by biopsy, and LCH was diagnosed by postoperative pathology 7 years prior. A systemic inspection showed suspicious lesions in the thyroid gland, liver, and the pituitary gland. Thyroid fine-needle aspiration (FNA) biopsy was performed, and a pathologic examination further confirmed
LCH. Therefore, the patient was clinically diagnosed with multi-system LCH involving "risk organs". The patient underwent several rounds of systemic chemotherapy, including vincristine $\left(150 \mathrm{mg} \mathrm{d}^{-3}\right)$ and prednisone $\left(1000 \mathrm{mg} \mathrm{d}^{-3}, \mathrm{q} 4 \mathrm{w}, 3\right.$ times); etoposide (150 $\left.\mathrm{mg} \mathrm{d}^{-3}\right)$ and prednisone (1000 $\mathrm{mg} \mathrm{d}^{-3}$, 1 time); and cytarabine (180 $\mathrm{mg} \mathrm{d} 1^{-5}, \mathrm{q} 4 \mathrm{w}, 10$ times), and she achieved clinical remission. A thyroid function test showed slight hypothyroidism, and thyroid ultrasonography revealed bilateral thyroid reduction with multiple nodules $(<0.5 \mathrm{~cm}$ in diameter) in the left lobe (Figure 1A). The patient was then prescribed levothyroxine $(50 \mu \mathrm{g} /$ day $)$ and desmopressin acetate $(0.075$ $\mathrm{mg} /$ day) for hypothyroidism and diabetes insipidus. After 1 year of follow up, magnetic resonance imaging (MRI) showed hypothalamic pituitary enlargement and increased number of liver nodules. Ultrasonography revealed that the thyroid gland was significantly larger than before (Figure 1B). The patient was given another dose of cytarabine chemotherapy $180 \mathrm{mg} \mathrm{d1}^{-5}$ and achieved partial remission. In spite of regular follow up, the patient suddenly presented with a painful neck swelling and progressive dyspnea and denied any form of trauma. The patient had received tracheal intubation at the local hospital before being referred to our hospital.

An initial examination revealed an obvious swelling in the anterior cervical region, which was tender to touch. A thyroid function test at admission reported severe hypothyroidism with a thyroid-stimulating hormone concentration of $8.45 \mathrm{mIU} / \mathrm{L}$ (normal range: $0.35-4.94 \mathrm{mIU} / \mathrm{L}$ ), a free thyroxine concentration of $6.46 \mathrm{pmol} / \mathrm{L}$ (normal range: 9.01-19.05 pmol/ $\mathrm{L}$ ), a total thyroxine of $45.28 \mathrm{nmol} / \mathrm{L}$ (normal range: 58.1-140.6 $\mathrm{nmol} / \mathrm{L}$ ), a free triiodothyronine concentration of $2.38 \mathrm{pmol} / \mathrm{L}$ (normal range: $2.63-5.70 \mathrm{pmol} / \mathrm{L}$ ), a total triiodothyronine concentration of $0.82 \mathrm{pmol} / \mathrm{L}$ (normal range: 0.89-2.44 pmol/ L). Neck computed tomography revealed bilateral diffuse goiter with hematoma. Contrast-enhanced computed tomography was
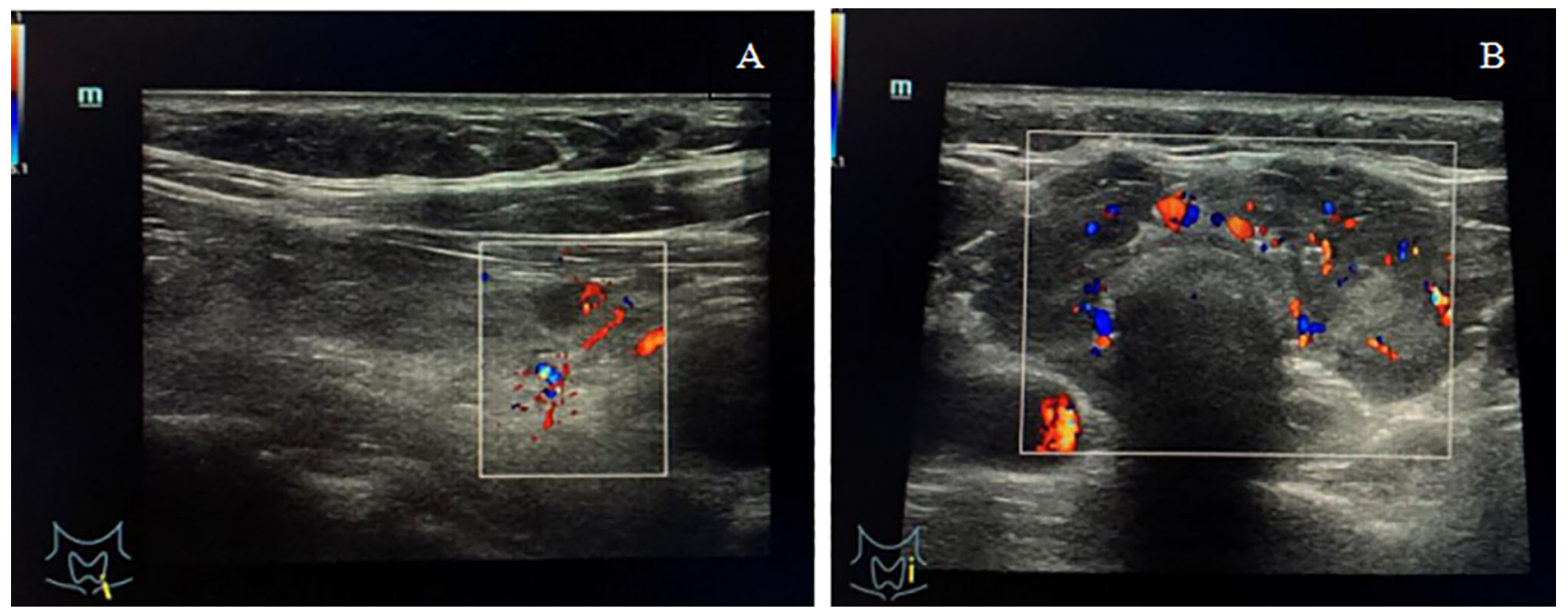

FIGURE 1 | (A) Ultrasonography showed bilateral thyroid reduction and multiple nodules $(<0.5 \mathrm{~cm}$ in diameter) in the left lobe with normal blood flow signals. (B) Ultrasonography showed thyroid enlargement with diffuse reduction in gland echo and abundant blood flow signals. 
rejected because of iodine allergy. A diagnosis of spontaneous thyroid hemorrhage was made based on the clinical symptoms and radiological findings.

\section{RESULTS}

\section{Case Treatments and Outcome}

The patient was transferred to the intensive care unit. During surgery, we observed massive blood clots causing surrounding tissues edema, while the thyroid gland was severely diminished and only partial thyroid tissue remained, which was fragile and easily bled upon touching, especially the thyroid isthmus. No active bleeding was found at that time. Thyroid isthmusectomy was performed, and the hematoma was removed. Prophylactic tracheotomy was performed in case of secondary postoperative bleeding and dyspnea. A pathological examination showed a classic phenotype with sheets and islands of nuclear atypical cells infiltration, with strongly positive immunochemical staining for CD1a, which confirmed the diagnosis of LCH. Meanwhile, immunochemical staining showed positive staining for CD56 and Ki-67 (Figure 2). The patient was successfully discharged from hospital 1 week after surgery. After 10 months, the tracheostomy cannula was removed, and the incision was healing well. Currently, the patient is under close follow-up.

\section{Thyroid LCH Involvement}

The PubMed, Web of Science and Medline databases were searched for articles published between January 1, 2010 and April 1, 2020, using the keywords: "thyroid" and "Langerhans cell histiocytosis", "Histiocytosis X”, "Eosinophilic Granuloma”, "Hand-Schüller-Christian disease", "Letterer-Siwe disease". And the references of each article were searched for further relevant publications. A total of 49 relevant articles were published between 2010 and 2020, but 22 articles were excluded due to incomplete information about the clinical feature and treatment of thyroid LCH. Therefore, in 27 articles, 29 cases of thyroid LCH involvement were reviewed (Table 1) (2-28). LCH involving the thyroid gland is more common in adults compared with children (25 adults vs. 4 children). Adult females are slightly more commonly affected than adult males (ratio of 1.27:1) (Table 2). Solitary thyroid involvement of $\mathrm{LCH}(24.14 \%)$ is rare and most cases $(75.86 \%)$ present as part of multi-system LCH (Table 2).

\section{Clinical Features}

Most cases of LCH involving the thyroid gland presented with goiter or diffuse thyroid enlargement (62.07\%). Almost one-third of cases present with a single thyroid nodule or multiple thyroid nodules $(37.93 \%)$. Fewer than half of cases occur in patients with euthyroidism (37.93\%), and one-third of cases occur in patients
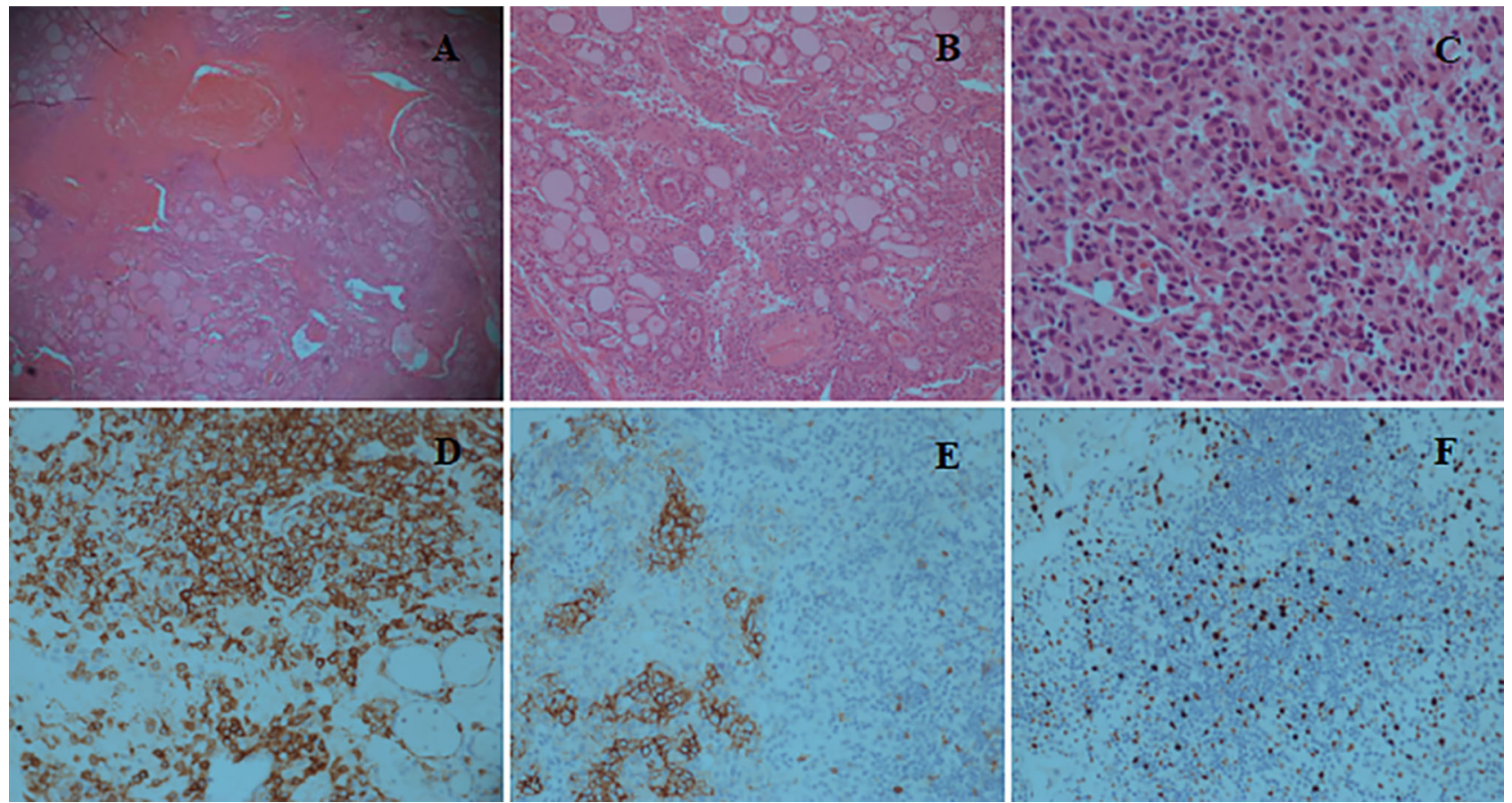

FIGURE 2 | (A) Hematoxylin and Eosin (H\&E) staining $(\times 5)$ reveals tissue necrosis and the infiltration composed of Langerhans cells, lymphocytes, and eosinophils. (B) H\&E staining $(\times 10)$ shows sheets and islands of nuclear atypia cells infiltration between the thyroid follicles. (C) H\&E staining ( $\times 40)$ reveals diffuse proliferation of nuclear atypia cells with typical nuclear grooves and indentation. (D) Immunochemical staining ( $\times 20)$ shows that Langerhans cells are strongly positive for CD1a, whereas thyroid follicular epithelial cells are negative. (E) Immunochemical staining $(\times 20)$ shows positive reaction for CD56. (F) Immunochemical staining ( $\times 20)$ shows slightly positive reaction for Ki-67. 
TABLE 1 | The cases of thyroid LCH involvement (in chronological order).

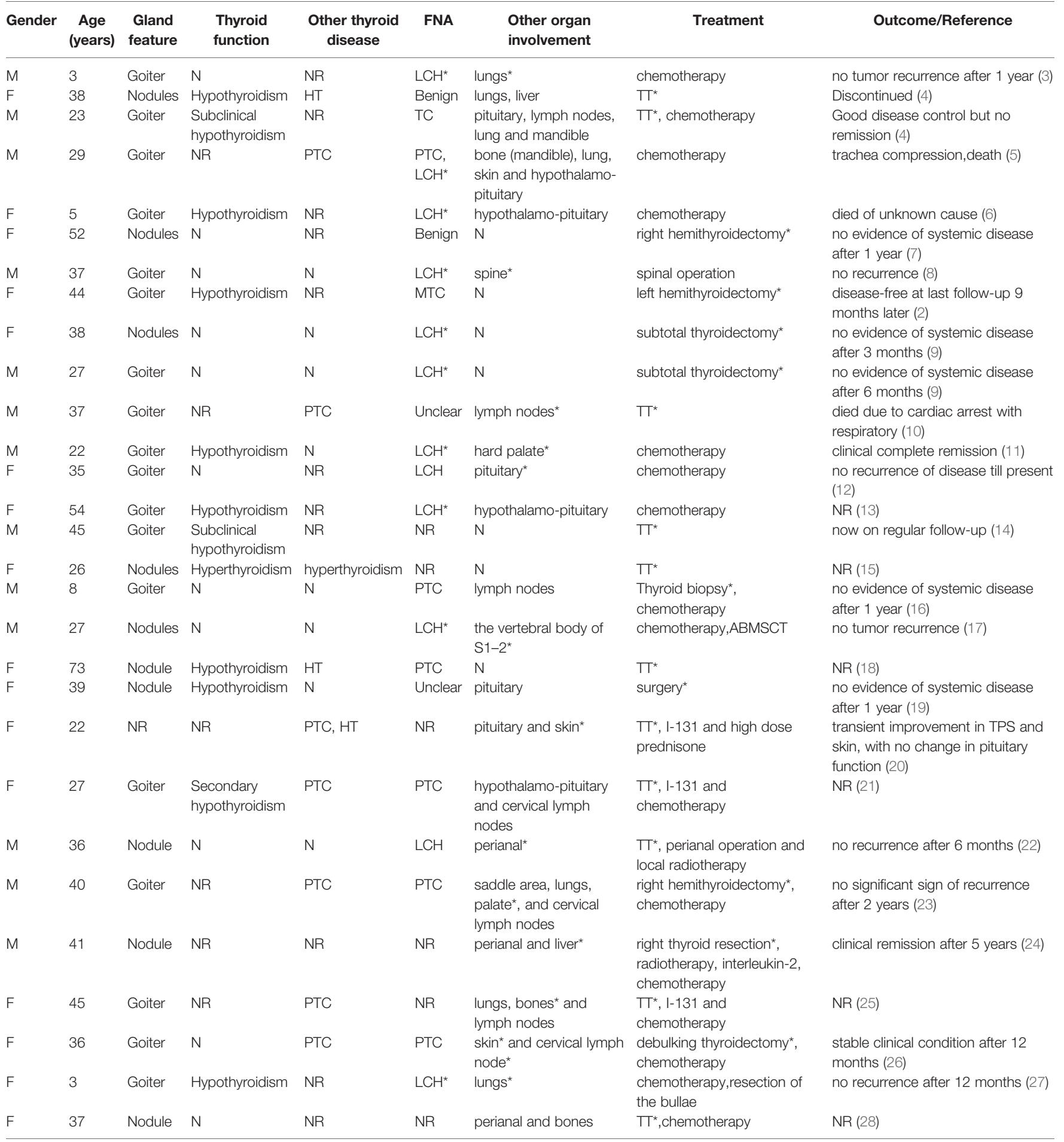

M, male; F, female; N, normal, NR, no report; HT, Hashimoto's thyroiditis; TC, thyroid carcinoma; PTC, papillary thyroid carcinoma; MTC, medullary thyroid carcinoma; TT, total thyroidectomy; *Pathologically confirmed $\mathrm{LCH}$.

with hypothyroidism (31.03\%). Subclinical hypothyroidism (6.9\%) and hyperthyroidism (3.45\%) are uncommon (Table 2). These presentations are nonspecific and can be easily confused with benign goiter or thyroid carcinoma.

\section{Diagnosis}

Thyroid FNA is useful to establish the primary diagnosis. However, the results of FNA are often variable, showing benign (6.9\%), papillary or medullary thyroid carcinoma (27.59\%), or atypical of 
TABLE 2 | The demography, clinicopathologic features, diagnose, treatment and outcome of patients with thyroid LCH involvement.

\begin{tabular}{|c|c|c|}
\hline Features & & Ratio \\
\hline \multirow[t]{3}{*}{ Patient(M:F) } & & $29(1: 1.23)$ \\
\hline & Child(M:F) & $4(1: 1)$ \\
\hline & Adult(M:F) & $25(1: 1.27)$ \\
\hline \multicolumn{3}{|c|}{ Thyroid gland } \\
\hline & Goiter & $62.07 \%(18 / 29)$ \\
\hline & Nodule(s) & $37.93 \%(11 / 29)$ \\
\hline \multicolumn{3}{|c|}{ Thyroid function } \\
\hline & $\mathrm{N}$ & $37.93 \%(11 / 29)$ \\
\hline & Hypothyroidism & $31.03 \%(9 / 29)$ \\
\hline & Hyperthyroidism & $3.45 \%(1 / 29)$ \\
\hline & Subclinical hypothyroidism & $6.9 \%(2 / 29)$ \\
\hline & $\mathrm{NR}$ & $20.69 \%(6 / 29)$ \\
\hline \multicolumn{3}{|c|}{ Other disease } \\
\hline & HT & $10.34 \%(3 / 29)$ \\
\hline & PTC & $24.14 \%(7 / 29)$ \\
\hline & PTC with HT & $3.45 \%(1 / 29)$ \\
\hline & Hyperthyroidism & $3.45 \%(1 / 29)$ \\
\hline & $\mathrm{N}$ & $27.59 \%(8 / 29)$ \\
\hline & NR & $37.93 \%(11 / 29)$ \\
\hline \multicolumn{3}{|l|}{ FNA } \\
\hline & $\mathrm{LCH}$ & $37.93 \%(11 / 29)$ \\
\hline & $\mathrm{TC}$ & $27.59 \%(8 / 29)$ \\
\hline & Benign & $6.9 \%(2 / 29)$ \\
\hline & Undetermined significance & $6.9 \%(2 / 29)$ \\
\hline & $\mathrm{NR}$ & $20.69 \%(6 / 29)$ \\
\hline \multicolumn{3}{|c|}{ Other involvement } \\
\hline & $\mathrm{N}$ & $24.14 \%(7 / 29)$ \\
\hline & Multisystem & $75.86 \%(22 / 29)$ \\
\hline \multicolumn{3}{|l|}{ Treatment } \\
\hline & Surgery of thyroid & $34.48 \%(10 / 29)$ \\
\hline & Chemotherapy & $31.03 \%(9 / 29)$ \\
\hline & Surgery+chemotherapy/radiotherapy & $31.03 \%(9 / 29)$ \\
\hline & Other & $3.45 \%(1 / 29)$ \\
\hline \multicolumn{3}{|c|}{ Treatment in adults } \\
\hline & Surgery of thyroid & $40 \%(10 / 25)$ \\
\hline & Chemotherapy & $20 \%(5 / 25)$ \\
\hline & Surgery+chemotherapy/radiotherapy & $36 \%(9 / 25)$ \\
\hline & Other & $4 \%(1 / 25)$ \\
\hline \multicolumn{3}{|c|}{ Treatment in children } \\
\hline & Chemotherapy & $100 \%(4 / 4)$ \\
\hline \multicolumn{3}{|l|}{ Outcome } \\
\hline & No recurrence & $58.62 \%(17 / 29)$ \\
\hline & Alive with tumor & $6.9 \%(2 / 29)$ \\
\hline & Death from tumor & $3.45 \%(1 / 29)$ \\
\hline & Death from other reason & $6.9 \%(2 / 29)$ \\
\hline & $\mathrm{NR}$ & $24.14 \%(7 / 29)$ \\
\hline
\end{tabular}

undermined significance (10.34\%) (Table 2). The golden standard for diagnosis of LCH is electronic microscopy (Birbeck granules) or immunohistochemical staining (S100 and CD1a positivity) (2). Coexistence of thyroid $\mathrm{LCH}$ involvement with other thyroid diseases, such as Hashimoto's thyroiditis (10.34\%) and papillary thyroid carcinoma (24.14\%), is not uncommon (Table 2).

\section{Treatment}

Of 29 patients, $10(34.48 \%)$ underwent surgical resection for thyroid involvement, 9 (31.03\%) underwent chemotherapy only, and $9(31.03 \%)$ underwent surgery and chemotherapy or radiotherapy. Seven patients $(24.14 \%)$ with solitary thyroid gland involvement with LCH underwent surgery only (Table 2).

\section{Outcome}

More than half of the patients (58.62\%) were followed up for 6 months to 5 years, and no evidence of disease recurrence was found. Two patients (6.9\%) were alive but did not achieve remission. Only 1 patient $(3.45 \%)$ died of disease recurrence (acute respiratory failure caused by the trachea compression and infiltration), whereas 2 patients (6.9\%) died of other causes. In addition, for the remaining cases $(24.14 \%)$, no follow-up outcome was reported (Table 2).

\section{DISCUSSION}

Langerhans cells are antigen-presenting cells resident in the epidermis, mucosae, or bronchial epithelium. LCH is a disease caused by the monoclonal proliferation of Langerhans cells. The annual incidence of $\mathrm{LCH}$ is 5 to $9 / 10^{6}$ in children younger than 15 years of age and 1 to $2 / 10^{6}$ in individuals older than 15 years of ages (29-31). The bones, skin, pituitary gland, liver, spleen, hematopoietic system, and lungs are most frequently affected by $\mathrm{LCH}$. Thyroid LCH involvement is not frequent, affecting 9\%$25 \%$ of individuals with LCH (32-35). To our knowledge, this is the first reported case of spontaneous hemorrhage caused by thyroid gland $\mathrm{LCH}$ in the literature.

For thyroid $\mathrm{LCH}$, the characteristic clinical feature is diffuse goiter or a painless thyroid mass. Laboratory tests of thyroid function in patients with $\mathrm{LCH}$ may be variable. With thyroid ultrasonography, $\mathrm{LCH}$ involvement can be manifested as solid hypoechoic nodules or diffuse reduction of gland echo, which can be easily misdiagnosed as multinodular goiter, Hashimoto's thyroiditis, thyroid cancer or lymphoma (9). In this case report, the patient presented with diffuse goiter and hypothyroidism at disease onset and was prescribed with oral levothyroxine to treat hypothyroidism. Thyroid hormone concentrations were maintained almost within the normal range (only free thyroxine was slightly lower at $8.90 \mathrm{pmol} / \mathrm{L}$ ). However, ultrasonography showed an increased in thyroid gland volume and laboratory tests showed a lower thyroid hormone concentration at follow up, which may indicate $\mathrm{LCH}$ progression. The patient may have suffered primary hypothyroidism (LCH thyroid involvement) combined with secondary hypothyroidism (LCH pituitary involvement), since the thyroid-stimulating hormone concentration was not high enough, while the thyroid hormone concentrations were relatively low at first visit. Thyroidstimulating hormone deficiency commonly develops in the context of hypopituitarism (33).

FNA might be helpful to diagnose of thyroid LCH (2). However, histology may be more sensitive as a diagnostic modality. To identify thyroid $\mathrm{LCH}$, infiltration of lymphocytes and eosinophils with large cytoplasm should be observed in the thyroid gland. LCH should be confirmed the presence of Birbeck granules using electron microscopy or immunohistochemical positivity for S100 and CD1a $(1,2)$.

There are available clinical guidelines for the treatment of pediatric LCH (34). However, there are no well-accepted treatments for adult $\mathrm{LCH}$ because of limited case studies and series (1, 36-38). Many clinical trials indicated that different lesion 
location and risk stratification can determine $\mathrm{LCH}$ treatment $(24$, 38). The liver, spleen and hematopoietic system are risk organs, which subdivide systemic LCH into high-risk and low-risk groups. The majority of cases of multi-system LCH involve at least one risk organ and indicate poor outcomes. For single-system thyroid $\mathrm{LCH}$, partial resection should be used for treatment, with or without radiotherapy or mild chemotherapy (39). For multisystem LCH, systematic chemotherapy is recommended. Lowrisk LCH should adopt low-dose and low-frequency chemotherapy to prevent diabetes insipidus or other late complications. Vinblastine combined with prednisone is the traditional chemotherapy regimen for pediatric LCH (40), while cytarabine might be better for adult LCH (36-38). On the contrary, high-risk LCH should adopt prolonged and intensive combination chemotherapy based on cladribine, cytarabine, 6mercaptopurine, and methotrexate to improve long-term survival $(41,42)$. Recent research shows that mutated $B R A F$ is presented in the majority of $\mathrm{LCH}$ cases and increases the risk of recurrence, suggesting that vemurafenib, which is an inhibitor of the B-Raf enzyme, can be used to treat $\operatorname{LCH}(1,43,44)$. An open-label nonrandomized study of 26 patients with BRAF V600-mutant $\mathrm{LCH}$ and Erdheim-Chester disease indicated that vemurafenib had prolonged efficacy, with a $62 \%$ confirmed overall response rate (45). Consistently, Donadieu et al. demonstrated that vemurafenib seem to be effective in children with refractory BRAFV600E-positive LCH (46). Prospective clinical trials are needed to determine the treatment duration for $\mathrm{LCH}$ patients.

However, definitive treatment for thyroid $\mathrm{LCH}$ is still controversial due to the lack of prospective randomized studies. Solitary thyroid LCH involvement is difficult to distinguish from other thyroid diseases, especially when it manifests as large goiter or painless nodules. Seven patients with solitary thyroid LCH involvement underwent surgery only, including hemithyroidectomy, subtotal thyroidectomy, or total thyroidectomy. In most of these cases (5 reported cases), no evidence of systemic disease or recurrence was noted (Table 1). There is no evidence to prove that adjuvant chemotherapy or radiotherapy after surgical resection improve the outcomes of primary thyroid $\mathrm{LCH}(2,5,7)$. Once thyroid $\mathrm{LCH}$ is diagnosed, it is necessary to perform systemic inspections, such as lung computed tomography, bone scintigraphy, liver ultrasonography, or positron emission tomography-computed tomography to definitively diagnose multi-system $\mathrm{LCH}$, which requires systemic therapy $(17,22)$. Chemotherapy regimens, such as vinblastine, etoposide, prednisone, and cytarabine have been used to treat aggressive disease. In our report, the patient was diagnosed with multi-system LCH affecting the uterus, thyroid gland, liver, and pituitary gland. The patient underwent systemic chemotherapy with different regimens, including vinblastine/prednisone, etoposide/prednisone, and cytarabine, and finally achieved clinical remission. After regular follow up, LCH recurrence occurred with thyroid gland enlargement and aggravated hypothyroidism, which finally caused spontaneous thyroid hemorrhage and dyspnea. Thus, close long-term follow up seems crucial.

Spontaneous thyroid hemorrhage is uncommon. Most cases occur following direct neck trauma or FNA; they rarely follow indirect trauma near the neck and an excessive Valsalva maneuvers (47-50). Aggressive goiter or malignant tumor can increase and alter thyroid gland vascularity (51-53). The risk of bleeding is increased due to immature angiogenesis, arteriovenous shunt, increased vascular flow, and thyroid gland fragility. Anticoagulants can also increase the severity of spontaneous bleeding (54). Elbers et al. (55) indicated that low thyroid hormone concentrations could shift the hemostatic system towards hypocoagulability and a hyperfibrinolytic state, which may increase the bleeding risk. The pathogenesis of thyroid hemorrhage in this case is hard to determined. It may have been associated with aggravated hypothyroidism and progressive diffuse goiter due to disease recurrence. Therefore, for patients with thyroid $\mathrm{LCH}$, active surveillance of thyroid hormone concentrations and thyroid gland volume is required, and a sufficient dose of levothyroxine is needed for patients with hypothyroidism. Spontaneous thyroid hemorrhage should be alerted when the treatment response is poor or when patients present with severe thyroid enlargement and hypothyroidism, which can cause obstructive symptoms even death.

\section{CONCLUSION}

Thyroid LCH is a rare disease. Spontaneous thyroid bleeding caused by thyroid LCH was first reported in this article. FNA and incision biopsy have a certain diagnostic value. Multi-system $\mathrm{LCH}$ should be evaluated by systemic examinations. Treatment options vary depending on the extent of disease. For thyroid $\mathrm{LCH}$, long-term active surveillance of thyroid hormone concentrations and thyroid gland volume is required. Clinicians should be alert of spontaneous thyroid bleeding, especially for patients with aggravated diffuse goiter and hypothyroidism. Further studies on treatments and surveillance for thyroid LCH are urgently needed.

\section{DATA AVAILABILITY STATEMENT}

The original contributions presented in the study are included in the article/supplementary material. Further inquiries can be directed to the corresponding author.

\section{ETHICS STATEMENT}

Written informed consent was obtained from the individual(s) for the publication of any potentially identifiable images or data included in this article.

\section{AUTHOR CONTRIBUTIONS}

$\mathrm{JZ}, \mathrm{CW}$, and ZL contributed to the study conception and design. $\mathrm{CW}, \mathrm{JZ}$, and CL searched prior articles and finished data analysis. $\mathrm{BB}, \mathrm{MY}$, and DX collected the clinical data. JZ and CW wrote the first draft of the manuscript. JZ revised the manuscript. All authors contributed to the article and approved the submitted version. 


\section{FUNDING}

This work was supported by the National Natural Science Foundation of China (81802334).

\section{REFERENCES}

1. Allen CE, Merad M, McClain KL. Langerhans-Cell Histiocytosis. N Engl J Med (2018) 379(9):856-68. doi: 10.1056/NEJMra1607548

2. Patten DK, Wani Z, Tolley N. Solitary Langerhans Histiocytosis of the Thyroid Gland: A Case Report and Literature Review. Head Neck Pathol (2012) 6(2):279-89. doi: 10.1007/s12105-011-0321-8

3. Lin $\mathrm{CH}$, Lin WC, Chiang IP, Ho YJ, Peng CT, Wu KH. Langerhans Cell Histiocytosis With Thyroid and Lung Involvement in a Child: A Case Report. J Pediatr Hematol/Oncol (2010) 32(4):309-311. doi: 10.1097/MPH. 0b013e3181c4dela

4. García Gallo MS, Martínez MP, Abalovich MS, Gutiérrez S, Guitelman MA. Endocrine Manifestations of Langerhans Cell Histiocytosis Diagnosed in Adults. Pituitary (2010) 13(4):298-303. doi: 10.1007/s11102-010-0233-8

5. Vergez S, Rouquette I, Ancey M, Serrano E, Caron P. Langerhans Cell Histiocytosis of the Thyroid Is a Rare Entity, But an Association With a Papillary Thyroid Carcinoma Is Often Described. Endocr Pathol (2010) 21 (4):274-6. doi: 10.1007/s12022-010-9134-7

6. Priyambada L, Bhatia V, Krishnani N, Agarwal V, Bhattacharyya A, Jain S, et al. Primary Hypothyroidism, Precocious Puberty and Hypothalamic Obesity in Langerhans Cell Histiocytosis. Indian J Pediatr (2011) 78 (3):351-3. doi: 10.1007/s12098-010-0271-2

7. Vilallonga R, Ciudin A, Fort JM, Baena JA, Gonzalez O, Armengol M, et al. Isolated Langerhans Cell Histiocytosis of the Thyroid in an Adult Female: One-Year Followup. Int J Endocrinol (2011) 2011:898302-2. doi: 10.1155/ 2011/898302

8. Mohd Ariff S, Joehaimey J, Ahmad Sabri O, Zulmi W. Langerhans Cell Histiocytosis With Extensive Spinal and Thyroid Gland Involvement Presenting With Quadriparesis: An Unusual Case in an Adult Patient. Malays Orthop J (2011) 5(3):28-31. doi: 10.5704/MOJ/1111.004

9. Chen ED, Cheng P, Cai YF, Xiang YY, Zheng HM, Xing HX, et al. Ultrasonographic Features of Langerhans Cell Histiocytosis of the Thyroid. Int J Clin Exp Pathol (2014) 7(3):1229-35.

10. Ceyran AB, Senol S, Bayraktar B, Ozkanlı S, Cinel ZL, Aydın A. Langerhans Cell Histiocytosis of the Thyroid With Multiple Cervical Lymph Node Involvement Accompanying Metastatic Thyroid Papillary Carcinoma. Case Rep Pathol (2014) 2014:184237-7. doi: 10.1155/2014/184237

11. Marupudi KC, Karanth SS, Thomas J. Langerhans Cell Histiocytosis Presenting as Hypothyroid Goitre: A Unique Presentation. BMJ Case Rep (2014) 2014:bcr2014206760. doi: 10.1136/bcr-2014-206760

12. Saqi A, Kuker AP, Ebner SA, Ausiello J, Jobanputra V, Bhagat G, et al. Langerhans Cell Histiocytosis: Diagnosis on Thyroid Aspirate and Review of the Literature. Head Neck Pathol (2015) 9(4):496-502. doi: 10.1007/s12105015-0608-2

13. Sangtian J, Riangwiwat T, Triamchaisri S, Kanoksil W, Sriphrapradang C. Fine-Needle Aspiration Biopsy of Langerhans Cell Histiocytosis of Thyroid Gland. J Clin Endocrinol Metab (2015) 100(1):15-6. doi: 10.1210/jc.2014-2859

14. Pandyaraj RA, Sathik Mohamed Masoodu K, Maniselvi S, Savitha S, Divya Devi H. Langerhans Cell Histiocytosis of Thyroid-a Diagnostic Dilemma. Indian J Surg (2015) 77(Suppl 1):49-51. doi: 10.1007/s12262-014-1118-2

15. Chrisoulidou A, Xirou P, Boudina M, Margaritidou E, Patakiouta F. Images in Endocrine Pathology: Isolated Langerhans Cell Histiocytosis of the Thyroid in a Patient With Autoimmune Thyroiditis and Hyperthyroidism. Endocr Pathol (2015) 26(3):276-8. doi: 10.1007/s12022-015-9369-4

16. Attakkil A, Thorawade V, Jagade M, Kar R, Parelkar K. Isolated Langerhans Histiocytosis in Thyroid: Thyroidectomy or Chemotherapy? J Clin Diagn Res (2015) 9(9):XD01-3. doi: 10.7860/JCDR/2015/12313.6466

17. Cai YF, Wang QX, Ni CJ, Dong SY, Lv L, Li Q, et al. A Case Report: The Diagnosis and Therapeutic Evaluation for a Rare Disease of Langerhans Cell Histiocytosis Involving Thyroid. Med (Baltimore) (2015) 94(44):e1891-1. doi: 10.1097/MD.0000000000001891

\section{ACKNOWLEDGMENTS}

The authors thank the patient who was glad to collaborate in the study.

18. Kuhn E, Ragazzi M, Zini M, Giordano D, Nicoli D, Piana S. Critical Pitfalls in the Use of BRAF Mutation as a Diagnostic Tool in Thyroid Nodules: A Case Report. Endocr Pathol (2016) 27(3):220-3. doi: 10.1007/s12022-016-9414-y

19. Skowronska-Jozwiak E, Sporny S, Szymanska-Duda J, Baranska D, Lewinski A. Hypopituitarism and Goitre as Endocrine Manifestation of Langerhans Cell Histiocytosis (LCH). Case Rep Neuro Endocrinol Lett (2016) 37(3):174-8.

20. Gordon MS, Gordon MB. Occult Langerhans Cell Histiocytosis Presenting With Papillary Thyroid Carcinoma, a Thickened Pituitary Stalk and Diabetes Insipidus. Case Rep Endocrinol (2016) 2016:5191903-5191903. doi: 10.1155/ 2016/5191903

21. AlZahrani R, Algarni M, Alhakami H, AlSubayea H, Alfattani N, Guler M, et al. Thyroid Langerhans Cell Histiocytosis and Papillary Thyroid Carcinoma. Gland Surg (2016) 5(5):537-40. doi: 10.21037/gs.2016.09.03

22. Gul OO, Sisman P, Cander S, et al. An Unusual Case of Adult-Onset MultiSystemic Langerhans Cell Histiocytosis With Perianal and Incident Thyroid Involvement. Endocrinol Diabetes Metab Case Rep (2017) 2017. doi: 10.1530/ edm-16-0087

23. Wu X, Chen S, Zhang LY, Luo YP, Jiang Y, Feng RE. Langerhans Cell Histiocytosis of the Thyroid Complicated by Papillary Thyroid Carcinoma: A Case Report and Brief Literature Review. Med (Baltimore) (2017) 96(35): e7954-4. doi: 10.1097/MD.0000000000007954

24. Xie J, Li Z, Tang Y. Successful Management of Multiple-Systemic Langerhans Cell Histiocytosis Involving Endocrine Organs in an Adult: A Case Report and Review of Literature. Med (Baltimore) (2018) 97(26):e11215-5. doi: 10.1097/ MD. 0000000000011215

25. Malik D, Kumar R, Mittal BR, Parkash G, Bal A, Bhattacharya A. Langerhans' Cell Histiocytosis Masquerading as Metastatic Papillary Thyroid Cancer on F18 Fdg PET/CT: Diagnostic Dilemma Solved by PET/CT-Guided Biopsy. Nucl Med Mol Imaging (2018) 52(5):394-7. doi: 10.1007/s13139-018-0536-7

26. Al Hamad M A, Albisher HM, Al Saeed WR, Almumtin AT, Allabbad FM, A Shawarby M. BRAF Gene Mutations in Synchronous Papillary Thyroid Carcinoma and Langerhans Cell Histiocytosis Co-Existing in the Thyroid Gland: A Case Report and Literature Review. BMC Cancer (2019) 19(1):170. doi: 10.1186/s12885-019-5372-3

27. Yokoyama S, Nakaoka T, Fukao D, Yokoyama K, Hara S, Hamahata K, et al. Pulmonary Langerhans Cell Histiocytosis With Thyroid Involvement Manifesting as Recurrent Bilateral Pneumothorax and Tension Bullae in a 3-Year-Old Child. Int J Surg Case Rep (2019) 60:239-43. doi: 10.1016/ j.ijscr.2019.06.027

28. Ben Nacef I, Mekni S, Mhedhebi C, Riahi I, Rojbi I, Nadia M, et al. Langerhans Cell Histiocytosis of the Thyroid Leading to the Diagnosis of a Disseminated Form. Case Rep Endocrinol (2020) 2020:6284764-6284764. doi: 10.1155/2020/ 6284764

29. Emile JF, Abla O, Fraitag S, Horne A, Haroche J, Donadieu J, et al. Revised Classification of Histiocytoses and Neoplasms of the Macrophage-Dendritic Cell Lineages. Blood (2016) 127(22):2672-81. doi: 10.1182/blood-2016-01690636

30. Kim H, Kim Y-J, Shin J, Min S, Kang SH, Suh JK, et al. Analysis of the Incidence and Diagnostic Pattern of Langerhans Cell Histiocytosis From the Population-Wide Healthcare Database in Korea. Blood (2019) 134 (Supplement_1):4866. doi: 10.1182/blood-2019-131531

31. Makras P, Stathi D, Yavropoulou M, Tsoli M, Kaltsas G. The Annual Incidence of Langerhans Cell Histiocytosis Among Adults Living in Greece. Pediatr Blood Cancer (2020) 67(9):e28422. doi: 10.1002/pbc.28422

32. Makras P, Samara C, Antoniou M, Zetos A, Papadogias D, Nikolakopoulou Z, et al. Evolving Radiological Features of Hypothalamo-Pituitary Lesions in Adult Patients With Langerhans Cell Histiocytosis (LCH). Neuroradiology (2006) 48(1):37-44. doi: 10.1007/s00234-005-0011-x

33. Kaltsas GA, Powles TB, Evanson J, Plowman PN, Drinkwater JE, Jenkins PJ, et al. Hypothalamo-Pituitary Abnormalities in Adult Patients With Langerhans Cell Histiocytosis: Clinical, Endocrinological, and Radiological 
Features and Response to Treatment. J Clin Endocrinol Metab (2000) 85 (4):1370-6. doi: 10.1210/jcem.85.4.6501

34. Aricò M, Girschikofsky M, Généreau T, Klersy C, McClain K, Grois N, et al. Langerhans Cell Histiocytosis in Adults. Report From the International Registry of the Histiocyte Society. Eur J Cancer (2003) 39(16):2341-8. doi: 10.1016/s0959-8049(03)00672-5

35. Han X, Ouyang M, Duan M, Zhang W, Zhu T, Li J, et al. The Combination of Methotrexate and Cytosine Arabinoside in Newly Diagnosed Adult Langerhans Cell Histiocytosis: A Prospective Phase II Interventional Clinical Trial. BMC Cancer (2020) 20(1):433-44. doi: 10.1186/s12885-020-06872-8

36. Girschikofsky M, Arico M, Castillo D, Chu A, Doberauer C, Fichter J, et al. Management of Adult Patients With Langerhans Cell Histiocytosis: Recommendations From an Expert Panel on Behalf of Euro-Histio-Net. Orphanet J Rare Dis (2013) 8:72-82. doi: 10.1186/1750-1172-8-72

37. Kobayashi M, Tojo A. Langerhans Cell Histiocytosis in Adults: Advances in Pathophysiology and Treatment. Cancer Sci (2018) 109(12):3707-13. doi: $10.1111 /$ cas.13817

38. Allen CE, Ladisch S, McClain KL. How I Treat Langerhans Cell Histiocytosis. Blood (2015) 126(1):26-35. doi: 10.1182/blood-2014-12-56930

39. Kasper EM, Aguirre-Padilla DH, Alter RY, Anderson M. Histiocytosis X: Characteristics, Behavior, and Treatments as Illustrated in a Case Series. Surg Neurol Int (2011) 2:57-61. doi: 10.4103/2152-7806.80122

40. Haupt R, Minkov M, Astigarraga I, Schäfer E, Nanduri V, Jubran R, et al. Langerhans Cell Histiocytosis (LCH): Guidelines for Diagnosis, Clinical Work-Up, and Treatment for Patients Till the Age of 18 Years. Pediatr Blood Cancer (2013) 60(2):175-84. doi: 10.1002/pbc.24367

41. Gadner H, Minkov M, Grois N, Pötschger U, Thiem E, Aricò M, et al. Therapy Prolongation Improves Outcome in Multisystem Langerhans Cell Histiocytosis. Blood (2013) 121(25):5006-14. doi: 10.1182/blood-2012-09-455774

42. Morimoto A, Shioda Y, Imamura T, Kudo K, Kawaguchi H, Sakashita K, et al. Intensified and Prolonged Therapy Comprising Cytarabine, Vincristine and Prednisolone Improves Outcome in Patients With Multisystem Langerhans Cell Histiocytosis: Results of the Japan Langerhans Cell Histiocytosis Study Group-02 Protocol Study. Int J Hematol (2016) 104(1):99-109. doi: 10.1007/ s12185-016-1993-3

43. Berres ML, Lim KPH, Peters T, Price J, Takizawa H, Salmon H, et al. BrafV600E Expression in Precursor Versus Differentiated Dendritic Cells Defines Clinically Distinct LCH Risk Groups. J Exp Med (2014) 211(4):669-83. doi: 10.1084/jem.20130977

44. Haroche J, Cohen-Aubart F, Emile JF, Arnaud L, Maksud P, Charlotte F, et al. Dramatic Efficacy of Vemurafenib in Both Multisystemic and Refractory Erdheim-Chester Disease and Langerhans Cell Histiocytosis Harboring the BRAF V600E Mutation. Blood (2013) 121(9):1495-500. doi: 10.1182/blood2012-07-446286

45. Diamond EL, Subbiah V, Lockhart AC, Blay JY, Puzanov I, Chau I, et al. Vemurafenib for BRAF V600-Mutant Erdheim-Chester Disease and Langerhans Cell Histiocytosis: Analysis of Data From the Histology-
Independent, Phase 2, Open-label Ve-BASKET Study. JAMA Oncol (2018) 4(3):384-8. doi: 10.1001/jamaoncol.2017.5029

46. Donadieu J, Larabi IA, Tardieu M, Visser J, Hutter C, Sieni E, et al. Vemurafenib for Refractory Multisystem Langerhans Cell Histiocytosis in Children: An International Observational Study. J Clin Oncol (2019) 137 (31):2857-65. doi: 10.1200/JCO.19.00456

47. Tsilchorozidou T, Vagropoulos I, Karagianidou C, Grigoriadis N. Huge Intrathyroidal Hematoma Causing Airway Obstruction: A Multidisciplinary Challenge. Thyroid: Off J Am Thyroid Assoc (2006) 16(8):795-9. doi: 10.1089/ thy.2006.16.795

48. Lemke J, Schreiber MN, Henne-Bruns D, Cammerer G, Hillenbrand A. Thyroid Gland Hemorrhage After Blunt Neck Trauma: Case Report and Review of the Literature. BMC Surg (2017) 17(1):115. doi: 10.1186/s12893017-0322-y

49. Hor T, Lahiri SW. Bilateral Thyroid Hematomas After Fine-Needle Aspiration Causing Acute Airway Obstruction. Thyroid (2008) 18(5):567-9. doi: $10.1089 /$ thy.2007.0363

50. Chartier LB, Turner JP. Delayed Intrathyroidal Hematoma Causing Respiratory Distress After a Seemingly Benign Fall: A Case Report. Int J Emerg Med (2010) 3(4):431-3. doi: 10.1007/s12245-010-0196-6

51. Testini M, Logoluso F, Lissidini G, Gurrado A, Campobasso G, Cortese R, et al. Emergency Total Thyroidectomy Due to non Traumatic Disease. Experience of a Surgical Unit and Literature Review. World J Emerg Surg (2012) 7:9-9. doi: 10.1186/1749-7922-7-9

52. Kumar S, Joshi MK. Emergency Total Thyroidectomy for Bleeding Anaplastic Thyroid Carcinoma: A Viable Option for Palliation. Indian J Palliat Care (2011) 17(1):67-9. doi: 10.4103/0973-1075.78452

53. Lee JK, Lee DH, Cho SW, Lim SC. Acute Airway Obstruction by Spontaneous Hemorrhage Into Thyroid Nodule. Indian J Otolaryngol Head Neck Surg (2011) 63(4):387-9. doi: 10.1007/s12070-011-0223-9

54. Gunasekaran K, Rudd KM, Murthi S, Kaatz S, Lone N. Spontaneous Thyroid Hemorrhage on Chronic Anticoagulation Therapy. Clin Pract (2017) 7 (1):932-2. doi: 10.4081/cp.2017.932

55. Elbers LPB, Fliers E, Cannegieter SC. The Influence of Thyroid Function on the Coagulation System and its Clinical Consequences. J Thromb Haemost (2018) 16(4):634-45. doi: 10.1111/jth.13970

Conflict of Interest: The authors declare that the research was conducted in the absence of any commercial or financial relationships that could be construed as a potential conflict of interest.

Copyright (c) 2021 Zhang, Wang, Lin, Bai, Ye, Xiang and Li. This is an open-access article distributed under the terms of the Creative Commons Attribution License (CC BY). The use, distribution or reproduction in other forums is permitted, provided the original author(s) and the copyright owner(s) are credited and that the original publication in this journal is cited, in accordance with accepted academic practice. No use, distribution or reproduction is permitted which does not comply with these terms. 